\title{
SUFRAGIO, VIRTUD CÍVICA Y MODELOS DE DEMOCRACIA*
}

\author{
Paula Ahumada Franco** \\ Universidad de Chile, Chile \\ paula.ahumada@gmail.com
}

\begin{abstract}
RESUMEN: El sufragio y la virtud cívica se vinculan con la participación política, y juegan diferentes roles dependiendo del enfoque que desde la filosofía política, se haga sobre el sistema democrático. En este trabajo se analiza sintéticamente el derecho de sufragio y la virtud cívica, desde la perspectiva liberal y republicana, lo que pretende ilustrar las complejidades de ambos dentro del proceso político. Posteriormente, se presentan estos dos elementos en relación con los diferentes y sucesivos modelos de democracia liberal que presenta C.B. Macpherson, para concluir que las proyecciones de un sistema democrático participativo requiere de ciudadanos que se conciban a sí mismos, más que como meros portadores de derechos, como miembros comprometidos con los asuntos públicos de su comunidad política.
\end{abstract}

Palabra clave: sufragio, virtud cívica, liberalismo, republicanismo, democracia

\section{SUFFRAGE, CIVIC VIRTUE AND MODELS OF DEMOCRACY}

ABSTRACT: Suffrage and civic virtue are connected to political participation and they play different roles depending on the political philosophy approach chosen to analyze the democratic system. In this work it is briefly analyzed from the liberal and republican approach, the right to vote and the civic virtue, expecting to inform about their complexities among the political process. Further, both elements are presented in relation with the different and consecutive models of liberal democracy of C.B. Macpherson. As a conclusion, the development of a participative democratic system, involves citizens who conceive themselves more than merely rights bearers, but as committed members in the public affairs of their political community.

Keywords: suffrage, civic virtue, liberalism, republicanism, democracy

Trabajo recibido el 19 de enero y aprobado el 19 de marzo de 2012.

** Abogado y Doctorando en Derecho, Facultad de Derecho de la Universidad de Chile; becaria del Programa MECE Educación Superior (2). 


\section{INTRODUCCIÓN}

Referirse al sufragio y a la virtud cívica nos lleva necesariamente al análisis del funcionamiento del sistema democrático. En efecto, la posición y función que cumplen tanto el derecho de sufragio como la virtud cívica en el sistema político constituyen un verdadero barómetro de la calidad y fortaleza de nuestra democracia. Así, para autores como Pablo Ruiz-Tagle ${ }^{1}$, el análisis de la función que cumple el derecho de sufragio en una sociedad política es un indicador relevante a la hora de caracterizar a un régimen fascista o autoritario.

Más aún, parece ser fundamental en el contexto de la democracia representativa, donde el derecho de sufragio aparece como central para su constitución y funcionamiento, toda vez que da lugar y habilita el procedimiento a través del cual los ciudadanos -libremente y considerados como sujetos iguales- eligen a sus representantes, y constituye al menos la forma básica de participación política. O también, al analizar el modelo de democracia elitista pluralista de equilibrio, como denominó C.B. Macpherson a la democracia procedimental schumpeteriana ${ }^{2}$. Pero, paradójicamente, cuando más la democracia se constituye como un sistema instrumental de elección de representantes, es decir, donde el sufragio resulta ser el elemento central, éste va perdiendo su sentido en la sociedad civil, decreciendo los niveles de participación electoral junto con la virtud cívica de los ciudadanos, entendida ésta como el compromiso participativo de todos en la resolución de los asuntos públicos.

En el contexto nacional se presenta un curioso sistema electoral que mezcla la inscripción voluntaria ${ }^{3}$ en los registros electorales por una sola vez, con la el sufragio obligatorio una vez inscrito. Este mecanismo institucional ha sido catalogado como una importante barrera de entrada de las personas a los procesos políticos electorales, que ha redundado en una baja sostenida en las inscripciones desde $1988^{4}$. Para hacer frente a esta disminución de la inscripción electoral, se dictó la ley $N^{\circ} 20.337$ en abril de 2009, garantizando la inscripción automática en los registros electorales y la voluntariedad del sufragio, modificando la norma constitucional que consagraba el voto obligatorio. De esta forma, el actual artículo 15 de la Constitución Política de la Repú-

1 Para Ruiz-TAgLe, la pregunta acerca de la función que se asigna al derecho de sufragio consistiría en un "verdadero 'test de embarazo' para detectar concepciones fascistas, antiliberales o autoritarias de los derechos fundamentales". Ruiz-TagLe, Pablo. "La contradicción del liberalismo católico en Chile". En: Estudios Públicos, 93 Santiago, Chile, (verano 2004), pp. 165-194.

2 Macpherson, C.B. La democracia liberal y su época. Madrid, España: Alianza Editorial, 2003. Joseph Schumpeter ha influido fuertemente en las teorías modernas de la democracia, especialmente en cuanto a su propuesta alternativa realista de democracia que realiza en su libro con su libro Capitalismo, Socialismo y Democracia (1943), donde prescinde de considerarla como una teoría de medios o de fines, centrándose en el proceso democrático, limitándola a un arreglo institucional para llegar a un cierto tipo de decisiones políticas. Pateman, Carol, Participation and Democratic Theory, Londres, Reino Unido: Cambridge University Press, 1970.

3 STC Rol N³8 (1986) considerando 11: "dicha inscripción en los Registros Electorales debe entenderse solo como una formalidad para atestiguar que se cumplen las exigencias constitucionales para ejercer el derecho de sufragio".

4 SaldaÑa, Jorge. "Participación y régimen electoral en Chile", en: Observatorio Electoral UDP, Documentos de Trabajo, Año 1, Número 1 (Oct. 2008); Navia, Patricio. "Participación electoral en Chile, 1988-2001", en: Revista de Ciencia Politica Vol. XXIV, $\mathrm{N}^{\circ} 1,2004$, pp.81-103. 
blica indica que "en las votaciones populares el sufragio será igualitario, secreto y voluntario". Esta modificación en nuestra institucionalidad -que aunque no ha tenido una aplicación concreta aún a la espera de ley orgánica constitucional que debe promulgarse-, llevó a un extenso debate a nivel académico y público acerca de la conveniencia o las desventajas de la instauración del voto voluntario en Chile. Más allá de lo interesante de los argumentos y de las consecuencias politológicas de uno y otro lado, surge la interrogante acerca de la naturaleza del derecho de sufragio, si constituye un derecho o un deber para el ciudadano, así como de la necesidad de participación de la ciudadanía en la resolución de los asuntos públicos. ¿Qué tan conveniente es la participación? Y si la respuesta a esta pregunta es que sí lo es, entonces, ¿`cuánta participación?

Las respuestas a las anteriores interrogantes dependen del sistema democrático que tenemos o queremos crear. Porque tanto el sufragio como la virtud cívica cumplen diferentes funciones dependiendo del modelo de democracia que se desarrolla en la sociedad y de la perspectiva asumida desde la filosofía política.

\section{LAS FACETAS DEL DERECHO DE SUFRAGIO. DERECHO SUBJETIVO E INTERÉS COLECTIVO}

Partiendo del sufragio entendido en su forma más básica, éste se identifica con el derecho a voto, y por lo tanto corresponde a una manifestación de la voluntad individual al interior de entes colegiados. En una primera instancia, podría ubicarse tanto en la esfera privada (derecho a voto, derecho a elección dentro de personas jurídicas como los distintos tipos de sociedades) como en la esfera pública (ya configurado como derecho político). Pero el derecho de sufragio considerado más ampliamente que el solo derecho a voto, como un derecho político, lo debemos ubicar en la esfera de lo público, toda vez que implica una facultad o autorización para participar en la producción del Derecho ${ }^{5}$. De acuerdo con Manuel Aragón, el derecho de sufragio propiamente tal, sería tan solo y siempre aquel cuando es atributo de ciudadanos, es decir, miembros de una comunidad política, para tomar decisiones políticas, esto es, que atañen al gobierno de la comunidad ${ }^{6}$. Por lo tanto, constituye un derecho de especiales características por cuanto se trata directamente de la relación del individuo con su comunidad. Como ejemplo de ello, en nuestra propia Constitución, el derecho de sufragio es un derecho fundamental que se encuentra regulado en los artículos 15 y 18, dentro del capítulo II titulado "Nacionalidad y Ciudadanía", y no en el capítulo III de nuestra Constitución que trata de "Los Derechos y Deberes constitucionales".

Cruz, Juan Antonio. El lenguaje de los derechos. Ensayo para una teoría estructural de los derechos, Madrid:Trotta, 2007, p. 31.

6 Aragón, Manuel. "Derecho de Sufragio: principio y función”, en: INTERNATIONAL IDEA, Treatise on Compared Electoral Law of Latinoamerica. Estocolmo, Suecia: International IDEA, 2007. 
El sufragio ha sido entendido como derecho subjetivo, pero también como deber, y finalmente, como una función dentro del Estado ${ }^{7}$. La forma como se caracteriza el derecho de sufragio implica también una definición de la filosofía política que sustenta cada posición ${ }^{8}$. Así, su configuración limitada al derecho subjetivo puede identificarse con una concepción liberalizante, mientras que su determinación como deber o la exaltación de la función que cumple el derecho de sufragio puede ser analizada desde el pensamiento republicano.

\section{I. Derecho de sufragio como derecho subjetivo: la perspectiva (neo)liberal}

En primer lugar, el derecho fundamental de sufragio como derecho subjetivo ${ }^{9}$, implica una facultad o poder de la persona para elegir a representantes políticos o para decidir cuestiones trascendentales para la comunidad, y constituye el derecho político por excelencia, considerado como el derecho a participar en el ejercicio del poder político como miembro de un cuerpo investido de autoridad política o como elector de sus miembros ${ }^{10}$. Otorga un ámbito de acción para el individuo que lo protege de interferencias de terceros y del Estado, amparando un espacio de libertad, entendida en su aspecto negativo, habilitando al ciudadano para poder decidir cuándo ser o no parte de la polis, cuándo manifestar la voluntad individual para la constitución de la voluntad politica.

Esta forma de concebir el derecho de sufragio desligado de la faceta del deber, corresponde también a la idea liberal clásica del sujeto aislado, atomizado y desvinculado de su comunidad. El ciudadano se considera como un yo individual, que así como puede elegir libremente, está también libre de obligaciones anteriores a los derechos o a cualquier acuerdo que tomemos $^{11}$. En esta misma línea entonces, aparece más evidente el planteamiento que hace Charles

7 Ver ZúNIIGA, Francisco. "Derecho de sufragio: la debatida cuestión de su obligatoriedad”, en: Estudios Constitucionales, Año 7, Nº1, 2009, pp.361-384. Talca, Chile: Centro de Estudios Constitucionales, Universidad de Talca.

8 Se debe tener en cuenta que existen diversas formas de republicanismos y de liberalismos. Para algunos, el republicanismo no sería una alternativa frente al liberalismo, sino que este último mantendría ideas propias del republicanismo clásico (VIroLi, Maurizio. Republicanism. Nueva York, Estados Unidos: Hill and Wang, 2002, p.6), mientras que en otros casos, el resurgimiento del republicanismo tiene lugar para contrarrestar el predominio liberal en la época moderna (Ovejero, Félix et al. La alternativa republicana. En: Ovejero, Félix et al. (comp.). Nuevas Ideas Republicanas. Autogobierno y libertad. Barcelona, España: Paidós, 2004, p. 15). Para poder efectuar un análisis comparativo del sufragio, se toman en cuenta características que se consideran determinantes para cada una de las tradiciones. En el caso del liberalismo, se analiza desde la vertiente neoliberal que extrema la protección de la libertad negativa y antepone los derechos a cualquier idea de deber. Mientras que la tradición republicana se identifica con la idea de autogobierno colectivo, desde la libertad positiva o política, o desde la libertad como no dominación.

9 En esta oportunidad por la extensión del tema, no se permite un mayor desarrollo en relación al concepto de derecho subjetivo. Sólo para dimensionar la complejidad de la discusión citamos a Michel Villey quien en un estudio acerca del concepto de derecho subjetivo en Ihering, hace referencia a la extensa literatura jurídico filosófica que existe, a la infinidad de definiciones, y para caracterizar la difícil problemática que se da en torno al concepto, alude a que Ihering también "chapoteó en este pantano". VILLEY, Michel. Estudios en torno a la noción de derechos subjetivos. Valparaíso, Chile: Ediciones Universitarias de Valparaíso, 1976, p. 225 y ss.

10 Marshall, T.H. Ciudadanía y Clase Social. Madrid, España: Alianza, 1998.

11 SANDEL, Michael, "La República procedimental y el yo desvinculado”, en: Nuevas Ideas Republicanas. Autogobierno y Libertad, Barcelona,España: Paidós, 2004, p. 90. 
Taylor en cuanto a que las doctrinas contractualistas -como lo son típicamente las liberales- establecen una primacía de los derechos, negando la misma jerarquía a un principio de pertenencia u obligación de la persona para con su sociedad ${ }^{12}$.

En este sentido, el ciudadano se considera tan solo como portador de derechos negativos, considerados como aquellas cartas de triunfo ${ }^{13}$ que se presentan contra el Estado y los demás ciudadanos, y donde los derechos políticos tienen la misma estructura que los demás derechos civiles, proveyendo de un espacio dentro del cual los sujetos son liberados de las presiones externas ${ }^{14}$, desconociendo la particularidad de los derechos políticos, en cuanto habilitadores para participar en la producción del Derecho.

En definitiva, desde el punto de vista liberal, el sufragio constituye un derecho subjetivo negativo que el ciudadano podría ejercer, pero nada ni nadie podría obligarlo a efectivamente hacerlo. La perspectiva del deber queda ausente en un análisis libertario y la configuración constitucional como un derecho voluntario, quedaría así justificada.

\subsection{EL DERECHO DE SUfRAGIO COMO FUNCIÓN Y DEBER: LA PERSPECTIVA REPUBLICANA}

Como derecho fundamental, el sufragio constituye una forma de limitar el poder, haciendo posible la responsabilidad política, por ejemplo, a través de la no reelección. Cumple también una función pública al crear órganos esenciales para el Estado ${ }^{15}$, ya que formaliza la representación política y garantiza jurídicamente el procedimiento de elección de representantes. Esta función pública ha sido entendida por algunos, como una función estatal que corresponde al ejercicio del poder de la colectividad, donde el ciudadano "ejerce una actividad estatal en nombre y por cuenta del Estado" 16 . Este ejercicio no podría ser facultativo para el ciudadano, y, tal como señala Kelsen, si "la función electoral es considerada como condición esencial para la vida del Estado, lo único consecuente es hacer del sufragio un deber del ciudadano, no solamente moral, sino que jurídico, es decir, establecer una sanción que habrá de ejecutarse contra el ciudadano que no ejercite la función de votar prescrita por la ley" (lo subrayado es mío) ${ }^{17}$.

Por su parte, considerando la dimensión objetiva institucional de los derechos fundamentales, el derecho de sufragio constituye un principio básico del sistema democrático, y hace posible -junto con otros elementos, por cierto- la expresión del pluralismo político, generando

\footnotetext{
12 TAYLor, Charles, “Atomismo”. En su: La libertad de los modernos, Buenos Aires, Argentina: Amorrortu, 2005 p. 226.

13 Dworkin, Ronald, Los derechos en serio, 4a reimpresión, Barcelona, Espańa: Ariel, 1999.

14 Habermas, Jurgen, "Soberanía popular: las versiones liberal y republicana". En: Ovejero, Félix et.al. (comp.), Nuevas Ideas Republicanas. Autogobierno y Libertad, Barcelona, Espańa: Paidós, 2004, p. 199.

15 Kelsen, Hans, Teoría General del Derecho y del Estado, 2a edición. D.F., México: UNAM, 1995, p. 348.

16 Carré de Malberg, Raymond, Teoría General del Estado, México, Fondo de Cultura Económica, 1948. citado en: ZúNína, Francisco, op. cit. (n.7), pp.361-384.

17 Kelsen, Hans, op. cit. (n.15), p.348.
} 
importantes bienes públicos, como lo son la estabilidad y legitimidad del sistema político. Estos importantes efectos que el sufragio produce sobre el sistema de gobierno, nos hace también desprender del mismo una función social ${ }^{18}$, que refuerza la concepción del mismo como un deber público o civico.

Esta faceta del sufragio, ha sido también parcialmente reconocida en nuestro país por el Tribunal Constitucional ${ }^{19}$, el cual explica las particulares características de este derecho en torno a su vinculación con el interés público: " $10^{\circ}$...Por ello [refiriéndose al voto] su exigibilidad y estricta observancia obedecen a claras motivaciones de interés público y en caso alguno constituyen una prerrogativa de simple incumbencia personal del sufragante, que éste pudiera renunciar o abdicar por su voluntad, como ocurre con los derechos que sólo miran a su propio interés."

La concepción del sufragio como deber y la consideración de la función social del mismo, nos acerca al pensamiento republicano. El republicanismo propone una forma de organizar la sociedad que importa una vinculación de la persona con la suerte de su comunidad ${ }^{20}$. Así, niega la visión atomista liberal del sujeto, y postula que éste se determina a través de sus relaciones sociales. Es como producto de un entramado de relaciones y de la vida al interior de la comunidad, que la persona se constituye como sujeto moral y como ciudadano, por lo cual, si bien se goza de derechos y beneficios así también se le imponen deberes que van más allá del deber de mero respeto a los derechos de los demás. Es la pertenencia a una comunidad la propia fuente de obligaciones que antecede a cualquier derecho que uno pudiera $\operatorname{tener}^{21}$, y al revés de la concepción liberal, esta obligación no se considera derivada de forma condicional a nuestro consentimiento o por ser beneficiosa para nosotros, sino que es intrínseca a nuestra capacidad de constituirnos como sujetos.

Por otra parte, el estatus de ciudadano no se encuentra determinado exclusivamente por el modelo de las libertades negativas, sino que implica también un haz de libertades positivas. El ideal republicano de la libertad considera que la concepción liberal de libertad es muy restrictiva y adhiere a un ideal de libertad vinculado directamente con el autogobierno, que demanda que las personas tengan la capacidad para participar en el gobierno tanto colectivo como individual. Entonces, en un sentido republicano, el derecho de sufragio lleva intrínseco en su

$18 \mathrm{Al}$ respecto, seguimos lo planteado por PeCES-BARBA, en cuanto a que todos los derechos tendrían una función social, dejando así de lado una concepción individualista de los derechos, acercándose a "una visión integral e institucional, donde todos los derechos se relacionan entre sí y se interinfluyen", Peces-barba Gregorio, Curso de Derechos Fundamentales. Teoría General. Madrid, España: Coedición de la Universidad Carlos III de Madrid y Boletín Oficial del Estado, 1999, p. 610.

19 STC Rol N 745-07, de 29 de marzo de 2007, en relación al examen de admisibilidad del proyecto de ley que modifica la Ley No 18.700, Orgánica Constitucional sobre Votaciones Populares y Escrutinios, con el objeto de reconocer el derecho a ser asistido en el acto de votar para las personas con discapacidad.

20 Ovejero, Félix, Incluso un pueblo de demonios: democracia, liberalismo, republicanismo. Madrid, España: Katz Editores, 2008, p. 14.

21 Cristi, Renato y Tranjan, J. Ricardo, "Charles Taylor y la democracia republicana”, en: Revista de Ciencia Politica, vol. 30, $\mathrm{N}^{\circ} 3,2010$, pp. 599-617. 
configuración un interés colectivo que impone también una obligación del sujeto con la colectividad, que va más allá del mero respeto del derecho de sufragio de los demás. En este caso, se justifica dentro del sistema democrático la obligatoriedad del derecho de sufragio.

\section{VIRTUD CÍVICA: MODELOS DE VIRTUD}

La virtud cívica es un término vinculado fuertemente con la tradición política republica$\mathrm{na}^{22}$, comprometida con un ideal de autogobierno colectivo que requiere de ciertas condiciones para llevarse a cabo, dentro de las cuales se encuentra el desarrollo de ciudadanos virtuosos. Tal como señala Rawls en su Liberalismo Político, para poder preservar los derechos y libertades de los ciudadanos en una sociedad democrática, éstos deben "tener en grado suficiente las 'virtudes políticas' (como las he llamado) y estar dispuestos a participar en la vida pública”23. Si bien se asocia a una cierta excelencia en el comportamiento público de los ciudadanos, vinculándola a valores cívicos como el coraje y la prudencia e incluso con valores como la igualdad, la simplicidad, honestidad, benevolencia, patriotismo, integridad, solidaridad, nobleza, abnegación o frugalidad, podemos resumirla como el compromiso con la suerte de los demás ${ }^{24}$.

En primera instancia podría parecer un término peligroso, ya que exigiría a los sujetos actuar de acuerdo a una determinada pauta moral, e impondría fuertes demandas sobre los ciudadanos, por lo cual no solo sería sospechosa por acercarse a un indeseado perfeccionismo moral, sino que también -desde el punto de vista instrumental- podría incluso ser considerada como innecesaria, ya que podría ser suplida por otros medios, como a través de las mismas instituciones.

Con todo, más allá de determinar cuáles características comprenden la virtud cívica y que hacen a las personas buenos ciudadanos, lo que es realmente definitorio de ella, es que trata de la relación del individuo con su propia comunidad política. Y puede ser caracterizada esencialmente por la disposición de anteponer el bien público a los intereses privados, lo cual evidentemente supone cierta predisposición de los ciudadanos a algunas de las cualidades ya mencionadas. En el fondo, la virtud cívica correspondería a una disposición pública ${ }^{25}$ que se manifiesta en el compromiso participativo de los ciudadanos con los intereses fundamentales de la sociedad, es decir, preferir el bien de la república aún por encima de sus propios intereses, ${ }^{26}$

\footnotetext{
22 Viroli, Maurizio, op. cit. (n.8), p. 79 y ss. Así también lo destaca Gordon Wood en su libro The creation of the American Republic: "el sacrificio de los intereses individuales al bien superior del conjunto era lo esencial del republicanismo y constituyó para los americanos la inspiración, el ideal, de su Revolución”. Citado en: Ovejero, Félix, op. cit. (n.20), p. 222.

23 Rawls, John, Liberalismo Político. D.F., México: Fondo de Cultura Económica, 2003, p. 198.

24 Gargarella, Roberto, Las teorías de la justicia después de Rawls. Un breve manual de filosofía política. Barcelona, España: Paidós, 1999, p. 164.

25 De acuerdo a Ovejero, el sentido más austero de la virtud cívica correspondería a esta disposición pública o sentimiento cívico. Ovejero, Félix, op. cit. (n.20), p. 53.

26 PeñA, Javier, "Ciudadanía republicana y virtud cívica”. En: Bertomeu, M.J., et.al (compiladores), Republicanismo y Democracia, Argentina, Mińo y Dávila editores, 2005, pp. 231-253.
} 
lo que los lleva entonces a participar dentro de la esfera pública. Por el contrario, el fracaso del desarrollo de un comportamiento virtuoso, eso es, el optar por la defensa de los propios intereses, sería una muestra de la corrupción del ciudadano ${ }^{27}$.

Pero para algunos, la virtud cívica es solo un medio para lograr objetivos superiores, como para el buen funcionamiento de la democracia, mientras que para otros, la participación sería positiva de forma intrínseca para todos aquellos que participan, e incluso hay quienes sostienen que una ciudadanía activa sería perjudicial para llegar a decisiones correctas. Esto se refleja en ciertos modelos de virtud ${ }^{28}$, construidos por Félix Ovejero en base a las diferentes posiciones desde la filosofía política, lo cual también permite analizar:

Liberal puro o de participación limitada: no confía en la participación. Mantiene una visión pesimista y cree que los ciudadanos carecen de vocación participativa, por lo tanto, tampoco serían virtuosos. Aboga por un debate racional y técnico dentro del sistema democrático, donde la participación no solo no es necesaria, sino que en exceso sería contraproducente. Se reduce la participación política al voto, y específicamente, al voto autointeresado. La participación sólo mantendría un carácter instrumental, ya que mediante la no reelección se castigaría a los representantes ineficientes.

Liberalismo igualitario o de participación instrumental: en este caso existe disposición a participar en los ciudadanos, pero no como una forma de realización personal, sino que para decidir correctamente y tomar decisiones en forma colectiva. La virtud, entonces, tiene un papel instrumental para la democracia, como lo es también la propia democracia, ya que se justificaría en la medida que genere leyes justas que aseguren la libertad. A pesar de este carácter instrumental de la participación y de la democracia, donde la obligatoriedad de votar podría ser justificada de forma instrumental, el énfasis de los derechos considerados en su faceta de derechos subjetivos, implicaría que tal obligatoriedad sería intromisión excesiva en la esfera de autonomía del sujeto.

Republicanismo autorrealizador o de participación intrínseca: la participación tiene valor en sí misma y existe una natural disposición de los ciudadanos hacia ella. La democracia se justificaría porque permite la realización de la participación y de la virtud. Se asume la existencia de unas capacidades naturales del ejercicio práctico y racional de "ser dueños de la propia vida", de una disposición hacia el autogobierno, lo que se realizaría en el espacio público. La participación sería inevitable, y el sufragio sería considerado como un deber.

Republicanismo comunitario o de participación obligatoria: defiende la importancia instrumental de la participación para el buen funcionamiento de la república, pero no cree en la

\footnotetext{
27 Ovejero, Félix et al., La alternativa republicana. En: Ovejero, Félix et al. (comp.). Nuevas Ideas Republicanas. Autogobierno y libertad, Barcelona, España: Paidós, 2004, p. 25.

28 Ovejero, Félix, op. cit. (n.20), p. 228 y ss.
} 
disposición participativa de los ciudadanos, por lo que sería el Estado el que debería promover las virtudes cívicas "obligando al ciudadano a ser libre", lo cual se correspondería además con el voto obligatorio.

\section{I. Motivaciones POlíticas: SUfRagio y ViRTUd}

Si la virtud cívica corresponde al compromiso participativo en los asuntos públicos, y el sufragio activo ${ }^{29}$ es la manifestación de la voluntad individual en la elección de representantes o respecto de la toma de decisiones públicas, podría parecer que existe entre ambas una relación de género (virtud) a especie (sufragio). Es decir, siempre que se ejerce el sufragio como forma de expresión de voluntad política, estaríamos ante un comportamiento comprendido dentro del concepto de virtud cívica. Sin embargo, esto no siempre es así. En efecto, al analizar los fundamentos del voto de los ciudadanos, podemos concluir que muchas veces se vota sin información suficiente o por razones autointeresadas que nada tienen que ver con lo que los republicanos considerarían como un comportamiento virtuoso.

Nuevamente, si nos preguntamos acerca de las motivaciones que tienen los ciudadanos al votar, la interrogante señalada se resuelve de dos formas, dependiendo del enfoque de la filosofía política liberal o republicana. Desde una perspectiva liberal, los electores votan y eligen de acuerdo a quienes mejor representan sus intereses particulares. Es a través de un mecanismo análogo al mercado competitivo, el medio por el cual se produce el bien público. En este sistema, los políticos candidatos presentan ciertas propuestas o realizan determinadas estrategias, a través de las cuales intentan captar los votos de los electores-consumidores, y estos últimos elegirán de acuerdo a quienes tienen un programa que se acomoda más a sus intereses particulares. Esto es lo que se ha llamado como la perspectiva de la preferencia ${ }^{30}$. Esta forma de elegir a los representantes resultaría beneficiosa ya que, bajo ciertos supuestos, resultaría elegido aquel que acumula la mayor cantidad de preferencias. Esta conclusión puede fundamentarse desde el utilitarismo, ya que la acumulación de preferencias redundaría en la decisión que produciría un mayor grado de felicidad general, o desde la propia filosofía libertaria, en cuanto nadie podría estar autorizado para decidir una política pública estatal, la agregación de preferencias individuales sería el mejor método de elección. De ambas formas, la perspectiva de la preferencia resulta independiente de toda virtud cívica.

Desde el republicanismo, en cambio, la democracia, los electores o los candidatos, no son considerados desde la perspectiva del mercado. En este caso, los ciudadanos tienen el deber de informarse y votar de acuerdo a lo que mejor satisface el bien general, el bien público. Aun-

29 Dentro del derecho de sufragio se distingue una faceta activa, que se entiende corresponde al derecho a elegir (representantes o tomar decisiones políticas) de una faceta pasiva, la cual implicaría el derecho a ser elegido.

30 Pettit, Philip, "Liberalismo y Republicanismo". En: Ovejero, Félix et al. (comp.). Nuevas Ideas Republicanas. Autogobierno y libertad, Barcelona, España: Paidós, 2004, p. 128 y ss; Brennan, Geoffrey y Peтtit, Philip, "Unveiling the vote”, en: British Journal of Political Science, vol. 20, N³...Cambridge University Press, Reino Unido, 1990, pp. 311-333. 
que ya no se participe directamente en la resolución de los asuntos públicos de la comunidad, al menos debe quedar virtud suficiente para poder elegir de acuerdo a la propuesta que más satisface el bien público. A lo anterior, Pettit lo ha denominado como la perspectiva del juicio. En este caso, los ciudadanos no serían considerados consumidores de un producto, sino más bien controladores de calidad, o miembros de un comité de selección, comprometidos con los intereses de la sociedad.

Esta segunda forma de votar, de acuerdo a la perspectiva del juicio o bien público, es la más exigente respecto del ciudadano, quien debe dejar de lado sus intereses particulares por lo que considera sería lo más beneficioso para el bien general. Por lo tanto, se requiere de ciudadanos virtuosos que puedan ejercer esta disposición pública al sufragar.

El acto de votar no sólo tiene sentido en cuanto afecta los propios intereses, sino porque resulta beneficioso para la comunidad en la que somos parte, contribuyendo a fortalecer la legitimidad del gobierno y porque es el acto político por excelencia dentro del sistema de democracia representativa. Tiene sentido más allá de una reducción del análisis político al funcionamiento de un mercado, que nos lleva a justificar la abstención de los ciudadanos en base a la aparición de los free riders, quienes en el cálculo de costo-beneficio que les significa particularmente ir a votar, prefieren abstenerse de hacerlo, porque de igual forma serán beneficiados por los bienes públicos que genera el voto de sus pares; esto es, la legitimidad y estabilidad del sistema.

Pero la perspectiva del juicio no sólo es exigente respecto de un ciudadano virtuoso, sino que plantea demandas sobre el sistema político y social. Necesariamente requiere de un correcto flujo de información a la ciudadanía, educación respecto a los temas públicos, y especialmente la generación de instancias de debate y discusión que puedan conducir a la formación del llamado juicio de la razón.

\section{SUFRAGIO Y VIRTUD EN RELACIÓN AL SISTEMA DEMOCRÁTICO}

Para finalizar, analizaremos la relación del sufragio y la virtud cívica con la democracia, y para ello nos centraremos en determinados modelos que presenta C.B. Macpherson (19111987), un autor que pretende rescatar lo que considera el aporte más positivo del liberalismo a la teoría democrática, esto es, el fundamento de la democracia como desarrollo ${ }^{31}$, y que desde nuestra perspectiva, resulta ser un acercamiento entre la tradición liberal y la republicana, especialmente su modelo de democracia participativa.

31 Macpherson, C.B., op. cit. (n.2), p. 147. 
En su libro La democracia liberal y su época, hace un análisis de la teoría democrática a partir del siglo $\mathrm{XIX}^{32}$, entendiendo a la democracia liberal en dos sentidos: como la democracia de una sociedad capitalista de mercado, y como la sociedad en la cual todos sus miembros tienen igual libertad para realizar sus capacidades ${ }^{33}$. Este análisis resulta especialmente relevante para el actual momento social chileno, toda vez que critica específicamente a aquella democracia liberal que asocia a una sociedad posesiva de mercado, esto es, a la sociedad capitalista ${ }^{34}$, y además, presenta su propuesta de un modelo de democracia participativa.

La aplicación de los modelos que presenta Macpherson permite apreciar los matices que tanto el sufragio como la virtud juegan dentro de las diferentes concepciones de democracia, en los sucesivos modelos denominados como la democracia "como protección", democracia "como desarrollo", democracia "como equilibrio", para terminar con su propuesta de democracia "como participación".

\section{I. La DEMOCRACIA COMO PROTECCIÓN}

Este modelo de democracia sirve de sustento a una sociedad industrial capitalista moderna, desarrollada en Europa e Inglaterra, y es promovido por autores como James Mill y Jeremy Bentham. Se basa en una visión pesimista de la persona, carente de virtud, considerando a los sujetos como "individuos conflictivos inherentemente egoístas de los que se suponen tienen un deseo infinito de obtener beneficios privados para sí mismos"35.

En su búsqueda de un sistema de gobierno que favoreciese una sociedad de mercado libre y, a su vez, protegiese a los ciudadanos del gobierno, el sufragio resulta central. Tanto James Mill como Bentham proponen argumentos a través de los cuales se defiende la idea de la universalidad del sufragio. Para Mill, todo aquel que no tenga poder político será oprimido por quienes sí lo tienen, y en este caso, el voto representa poder político, y la falta de voto es falta de

32 La democracia en el mundo antiguo habría presupuesto una ciudadanía formada por personas no sujetas o dependientes al empleo por cuenta ajena, mientras que en la Edad media no se encuentra ninguna teoría de la democracia ni exigencia de derecho democrático de voto, ya que el poder no residía en órganos electivos y el poder en el feudalismo dependía de la posición social "ningún movimiento popular, por enfurecido que fuese, se iba a imaginar que podía lograr sus objetivos si conseguía el voto". En el siglo XVI y XVII las teorías democráticas se basaban en sociedades sin clase y donde no existiese la propiedad privada. En otros casos, se vinculaba el derecho de propiedad con el derecho de sufragio, como cierta interpretación que se hace respecto de los niveladores (levellers), que buscaban excluir a los mendigos y asalariados del derecho de voto, mientras que otra posición seńala que el ideal de los niveladores era que todas las personas tuviesen suficiente propiedad para trabajar como productores independientes y de esta forma que ningún grupo pudiese transformarse en una clase explotadora. En el siglo XVIII destacan las teorías de Rousseau y Jefferson que también apelaban a una sociedad de productores económicamente independientes. MACPHerson, C.B., op. cit. (n.2), pp. 24-28.

33 Macpherson, C.B., op .cit. (n.2), p.9.

34 Ruiz, Carlos, "Individualismo posesivo, Liberalismo y Democracia Liberal. C.B. Macpherson y la Teoría Democrática”. En su: Seis Ensayos sobre Teoría de la Democracia, Santiago, Chile: Universidad Nacional Andrés Bello, 1993, p. 26.

35 Macpherson, C.B., op. cit. (n.2), p. 60. 
poder político. Por lo tanto, todo lo que no correspondiese a un voto por persona sería inútil en principio para proteger a todos los ciudadanos del gobierno, ya que eventualmente a través del voto se podría derrocar o cambiar de gobierno.

Bentham por su parte, si bien no era partidario del sufragio universal, también se veía obligado a aceptarlo (siempre con limitaciones), en base a un razonamiento fundado en la protección: "la única forma de impedir que el gobierno desposea al resto de la gente es hacer que la mayoría de toda la gente pueda revocar con frecuencia a los gobernantes" 36 .

Sin embargo, esto no significa que se apelara a un voto universal ni que se tratara de un espíritu de igualdad. Es más, se propusieron diferentes fórmulas para limitar el sufragio, excluyendo a aquellos individuos cuyos intereses se puedan considerar incluidos dentro de los intereses de otros, dejando fuera a las mujeres, a los jóvenes, y a los más pobres ${ }^{37}$.

En este modelo, el valor principal resulta ser el de la seguridad y su principal objetivo es lograr un gobierno estable, mientras que la visión autointeresada de los ciudadanos excluye a la virtud cívica de todo análisis.

\subsection{La DEMOCRACIA COMO DESARROLLO}

John Stuart Mill es el principal precursor de este modelo, el cual se distingue del anterior tanto en el objetivo que persigue el sistema democrático, como en la concepción de persona en la que se basa. El objetivo del sistema político democrático pasó de ser la defensa y seguridad de la persona, a la contribución al progreso del ser humano, e implica la posibilidad que la sociedad mejore en base a un aumento en la cantidad de desarrollo de la propia personalidad de todos los miembros de la sociedad. Sería este régimen político el que promovería "el avance de la comunidad [...] en intelecto, virtud, actividad práctica y eficacia" 38 . En segundo lugar, la base del modelo deja de ser la persona como consumidor o apropiador egoísta del modelo anterior, sino alguien capaz de ejercer, desarrollar y disfrutar de sus capacidades robustecidas por el sistema democrático.

La democracia otorga a todos un interés directo en los actos de gobierno y un incentivo para participar activamente, por lo menos hasta el punto de votar por el gobierno, informarse, formar sus opiniones, etc., lo cual haría que las personas fuesen más activas y enérgicas, avanzando en cuanto al "intelecto, virtud, actividad práctica y eficacia" 39 , donde la participación en el proceso político mejoraría la calidad de las personas, al aumentar en cada acto de participación el apetito por más participación.

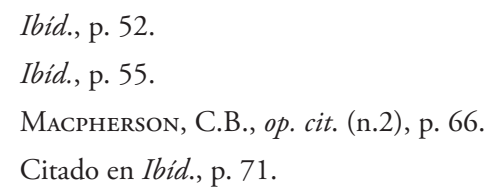


Sin embargo, J.S. Mill tampoco estaba a favor de la igualdad en el derecho de sufragio. Consideraba que dadas las condiciones de inequidad en las que se encontraban los trabajadores, éstos no podrían ejercer de buena forma el poder político, ya que se guiarían al actuar por sus propios intereses inmediatos ${ }^{40}$. Como la sociedad para Mill estaba dividida en dos clases (la trabajadora y la propietaria) pensaba que en caso que el sufragio se otorgase a todos, se generaría una legislación de clase, por lo que se inclinaba por el establecimiento del voto plural, dando importancia a la especialización y al conocimiento.

\subsection{LA DEMOCRACIA COMO EQUILIBRIO}

El modelo elitista pluralista de equilibrio es descrito con gran precisión por Joseph Schumpeter quien señala que la democracia sería "aquel arreglo institucional para llegar a decisiones políticas en el que los individuos adquieren poder para decidir mediante una lucha competitiva por el voto del pueblo" 41 .

La democracia no sería más que un mecanismo para elegir y autorizar gobiernos (no es un tipo de sociedad o conjunto de valores). Se desprende todo elemento sustantivo de la democracia, convirtiendo a la misma en un procedimiento institucional de toma de decisiones. El objetivo de la democracia ya no es hacer mejores ciudadanos ni promover su desarrollo, sino que su principal objetivo debe ser el tomar y procesar los deseos (demandas) de la gente como es, pero no contribuir a lo que debería ser.

Se trata a los ciudadanos como meros consumidores donde su papel ya no es el de decidir cuestiones políticas, sino que simplemente consiste en elegir a las personas que adoptarán esas decisiones. Luego, es solo través del sufragio como el pueblo se protege de la tiranía del gobierno.

La participación en la esfera política se reduce al acto de votar, existiendo un verdadero ámbito de economía de la virtud ${ }^{42}$, dejando de ser un valor en sí misma, ni siquiera un valor instrumental para que los individuos como un todo pudiesen tener más conciencia social. La sociedad política se la hace análoga al mercado, en cuanto a las relaciones entre los ciudadanos y los proveedores de las mercancías políticas, siendo el motor del sistema la competencia entre dos o más grupos de políticos (elites) organizados en partidos políticos, por los votos de los electores. Este modelo requiere de niveles de apatía, ya que una participación mayor desestabilizaría al sistema, por lo que se promueve la generación de ciudadanos pasivos frente a los problemas públicos, siendo su papel análogo al de los consumidores, como en el modelo de la democracia como protección.

\footnotetext{
$40 \quad$ Ibid., p. 76.

41 Cohen J. L. y Arato A.: Sociedad Civil y Teoría Política. D. F., México: Fondo de Cultura Económica, 2000, p. 23 y ss.

42 Ovejero, Félix, La libertad inhóspita: Modelos humanos y democracia liberal. Madrid, España: Paidós, 2002, p. 159.
} 


\subsection{La DEMOCRACIA COMO PARTICIPACIÓN}

La propuesta participativa de Macpherson, rescata lo que considera uno de los aportes más positivos de la democracia liberal, cual es el significado de la participación en el modelo de democracia como desarrollo, donde la democracia vuelve a tener como objetivo el incremento y el desenvolvimiento de las capacidades humanas.

Este modelo habría surgido de las aspiraciones del moviendo estudiantil de la Nueva Izquierda durante los años sesenta, para luego difundirse entre la clase trabajadora durante los setenta ${ }^{43}$. Esta idea de mayor participación de los ciudadanos en las decisiones del gobierno se extendió también dentro de los mismos programas de los gobiernos de la época.

Ciertamente, el modelo participativo no es equivalente al establecimiento de una democracia directa, ya que se reconoce la imposibilidad de una democracia participativa a escala masiva, incluso asumiendo los avances en la tecnología. Es decir, si a través de mecanismos tecnológicos fuese posible realizar plebiscitos en línea respecto de las más diversas materias, siempre algún órgano estatal debería estar mandatado para plantear las preguntas, lo que no podría ser delegado a organismos de carácter privado.

Según Macpherson, la concepción de la persona y la inclinación al autodesarrollo presente en la tradición del pensamiento liberal, ha sido obstaculizada por la sociedad posesiva de mercado que privilegia un modelo que centra su análisis en el poder extractivo, donde el poder fundamental sería el poder que se ejerce sobre los demás, coherente con la imagen del sujeto como apropiador o consumidor infinito del modelo de la democracia como protección o equilibrio $^{44}$. Frente a ello, propone que sea el poder de autodesarrollo el motor y fin de la democracia, y para que ello ocurra se requiere de una sociedad donde exista un acceso igualitario a los medios de vida y trabajo.

Sin embargo, más que la construcción teórica del modelo participativo y la determinación de sus particulares características, lo difícil resultaría salir del círculo vicioso que nos mantendría en una democracia de carácter elitista o de equilibrio. Para ello se requeriría de dos condiciones: la primera, corresponde a un cambio en la conciencia de los ciudadanos de sus propias necesidades, donde las personas pasaran de verse a sí mismas como consumidores, a actuar como personas que ejercitan sus propias capacidades y gozan con el ejercicio y disfrute de ellas. Este requisito no solo es necesario para llegar a la democracia participativa, sino que debe permanecer en ella, e importa un sentimiento de comunidad, mucho más fuerte que el actual, que se puede relacionar con la necesidad de una mayor virtud cívica en los ciudadanos y que se

43 Macpherson, C.B., op. cit. (n.2), p. 121.

44 Ruiz, Carlos, op. cit. (n.34), p. 45. 
encuentra con las ideas más clásicas del republicanismo. En segundo lugar, se necesitaría de una reducción de la desigualdad social y económica, planteando una vinculación entre esta última con la baja participación política.

Ahora bien, el diagnóstico que hace Macpherson no es desesperanzador y, más aún, altamente pertinente al contexto nacional. Así, existirían tres grandes debilidades que juntas conducirían a una reducción de la conciencia de consumidores, disminución de la desigualdad, y a un aumento en la participación política: la conciencia cada vez mayor de los costos del crecimiento económico, lo cual implicaría que las personas adquieran la conciencia de ser algo más que meras consumidoras, y asumieran la importancia del interés público, que no puede satisfacerse con el interés particular de cada consumidor ni con la competencia entre las elites del modelo de equilibrio; la conciencia de los costos que trae la apatía política y la insuficiencia de las formas tradicionales y rutinarias de la acción colectiva, como lo es, la participación exclusivamente a través del sufragio; y la desconfianza en la capacidad del capitalismo para satisfacer las expectativas de los consumidores a la vez que genera y reproduce la desigualdad.

\section{CONCLUSIONES}

El buen funcionamiento y la estabilidad de las democracias modernas no sólo dependen de sus instituciones, sino que en parte importante se trata de las cualidades y actitudes que tengan y que asuman sus ciudadanos ${ }^{45}$. No basta con tener los adecuados instrumentos institucionales para limitar el poder, si los ciudadanos no hacen efectivos los mecanismos de rendición de cuentas, si no ejercen el sufragio, si prima la apatía y no existe memoria ni espíritu colectivo. Se requiere del ejercicio del sufragio, pero no de cualquier tipo de voto. Es necesario un mínimo de virtud cívica que implique abandonar una perspectiva de la preferencia y comprometerse con la perspectiva del juicio.

Diferentes modelos de democracia asumen diferentes perspectivas acerca del sufragio y de la virtud de sus ciudadanos. Pero en el contexto actual, parece interesante la visión de Macpherson sobre la democracia participativa. Aquella que rescata lo más valioso de la tradición liberal, en cuanto a entender a la democracia como un sistema político que habilita el desarrollo de sus ciudadanos, pero que no solo asume la igualdad y la universalidad del derecho de sufragio, sino que importa mayores grados de participación política. Hoy más que nunca el sistema de la democracia delegada o representativa es preocupante si el espacio público y de participación política queda reducido exclusivamente al voto, y en las circunstancias modernas, bien podría ser ésta la hipótesis. Esta aprehensión frente al sistema representativo fue manifestada por Jefferson, quien de acuerdo a Hannah Arendt:

45 Kyмlicka, Will, Ciudadanía multicultural. Barcelona, España: Paidós, 1996, p. 241. 
"se dio cuenta de que el peligro mortal para la república consistía en que la Constitución había dado todo el poder a los ciudadanos sin darles la oportunidad de ser republicanos o de actuar como ciudadanos. En otras palabras, el peligro consistía en haber dado todo el poder al pueblo a título privado y no haber establecido ningún espacio donde pudieran conducirse como ciudadanos" 46 .

En resumen, haber otorgado el derecho al voto, restringiendo la actividad pública de los ciudadanos a las elecciones, y no fortaleciendo otras formas de participación en la esfera pública.

Para llegar a una democracia participativa, se requiere un cambio en la conciencia de los ciudadanos. Es decir, es necesario que los ciudadanos se conciban a sí mismos más que como meros portadores de derechos y libertades negativas, y se asuman como miembros comprometidos con los asuntos públicos de su comunidad. En el ejercicio de la ciudadanía, entendida ésta como participación en los asuntos públicos, e identificada con el ejercicio de la virtud cívica, las personas encuentran algo más que un instrumento para sus propios fines como individuos privados, constituyendo un modo de vivir dignamente como sujetos autónomos y no como súbditos. Como dijo Maquiavelo, "defender la república" es el mejor modo de asegurar la "libertad de cada uno" 47 . Así también, es la libertad de la república la que se debe preservar, y su conservación depende del grado de vigilancia y de atención que los ciudadanos pongan en las materias de interés público.

Sin embargo, queda latente el círculo vicioso, ese estado de cosas basado en la desigualdad social y económica que impide avanzar hacia un sistema participativo. Con todo, si observamos el revuelo social que se sucede en diversas partes del mundo y en Chile, podemos advertir que ciertas conclusiones de Macpherson resultan ser bastante pertinentes. Porque muchas de las protestas y manifestaciones públicas tratan precisamente de la conciencia cada vez mayor de los costos del crecimiento económico, de la apatía política, y la desconfianza en la capacidad del capitalismo como modelo económico. Por lo tanto, cabe preguntarnos qué tan cerca estamos de lograr establecer un sistema democrático participativo, y de pensar seriamente en sus características.

\section{REFERENCIAS BIBLIOGRÁFICAS}

Aragón, Manuel, "Derecho de Sufragio: principio y función”, en: INTERNATIONAL IDEA, Treatise on Compared Electoral Law of Latinoamérica. Estocolmo, Suecia: International IDEA, 2007.

Brennan, Geoffrey y Pettit, Philip, "Unveiling the vote", en: British Journal of Political Science, vol. 20, №3... Cambridge University Press, Reino Unido, 1990, pp. 311-333.

\footnotetext{
VAllespín, Fernando, “Hannah Arendt y el Republicanismo”. En: Cruz, Manuel (comp.) El siglo de Hannah Arendt. Barcelona, España: Paidós, 2006, p. 135.

47 "Sólo en la república libre, cuando los ciudadanos se muestran vigilantes, se evita que los intrigantes grandi gobiernen conforme a sus propios deseos", Ovejero, Félix, op. cit. (n.20) p. 222.
} 
Cohen Jean L. y Arato Andrew, Sociedad Civil y Teoría Política. D.F., México: Fondo de Cultura Económica, 2000.

Cristi, Renato y Tranjan, J. Ricardo, “Charles Taylor y la democracia republicana”, en: Revista de Ciencia Política, vol. 30, N³, Santiago, Chile, 2010.

Cruz, Juan Antonio, El lenguaje de los derechos. Ensayo para una teoría estructural de los derechos, Madrid, España: Trotta, 2007.

Dworkin, Ronald, Los derechos en serio, $-4^{\mathrm{a}}$ reimpresión-. Barcelona, España: Ariel, 1999.

Habermas, Jurgen, “Soberanía popular: las versiones liberal y republicana”. En: Ovejero, Félix et al. (comp.), Nuevas Ideas Republicanas. Autogobierno y Libertad, Barcelona, España: Paidós, 2004.

Kelsen, Hans, Teoría General del Derecho y del Estado, -2a edición-. D.F., México: UNAM, 1995.

Kyмlicka, Will, Ciudadanía multicultural. Barcelona, España: Paidós, 1996.

Navia, Patricio, "Participación electoral en Chile, 1988-2001", en: Revista de Ciencia Política Vol. XXIV, N¹, 2004.

Macpherson, C.B., La democracia liberal y su época. Madrid, España: Alianza, 2003.

Marshall, T.H., Ciudadanía y Clase Social. Madrid, España: Alianza, 1998.

Ovejero, Félix et.al., La alternativa republicana. En: Ovejero, Félix et.al. (comp.). Nuevas Ideas Republicanas. Autogobierno y libertad, Barcelona, España: Paidós, 2004.

La libertad inhóspita: Modelos humanos y democracia liberal, Madrid, España: Paidós, 2002.

Incluso un pueblo de demonios: democracia, liberalismo, republicanismo. Madrid, España: Katz Editores, 2008.

Pateman, Carol, Participation and Democratic Theory. Londres, Reino Unido: Cambridge University Press, 1970.

Peces-barba Gregorio, Curso de Derechos Fundamentales. Teoría General. Madrid, España: Coedición de la Universidad Carlos III de Madrid y Boletín Oficial del Estado, 1999.

Petтiт, Philip, "Liberalismo y Republicanismo". En: Ovejero, Félix et al. (comp.). Nuevas Ideas Republicanas. Autogobierno y libertad, Barcelona, España: Paidós, 2004.

Ruız, Carlos, "Individualismo posesivo, Liberalismo y Democracia Liberal. C.B. Macpherson y la Teoría Democrática". En su: Seis Ensayos sobre Teoría de la Democracia, Santiago, Chile: Universidad Nacional Andrés Bello, 1993.

Ruiz-Tagle, Pablo, "La contradicción del liberalismo católico en Chile”. En: Estudios Públicos, 93, Santiago, Chile, (verano 2004).

SALDAÑA, Jorge, "Participación y régimen electoral en Chile", en: Observatorio Electoral UDP, Documentos de Trabajo, Año 1, Número 1 (Oct. 2008).

SAndel, Michael, "La República procedimental y el yo desvinculado", en: Nuevas Ideas Republicanas. Autogobierno y Libertad, Barcelona, España: Paidós, 2004.

VAllespín, Fernando, "Hannah Arendt y el Republicanismo”. En: Cruz, Manuel (comp.) El siglo de Hannah Arendt,. Barcelona, España: Paidós, 2006.

Villey, Michel, Estudios en torno a la noción de derechos subjetivos, Valparaíso, Chile: Ediciones Universitarias de Valparaíso, 1976.

Viroli, Maurizio, Republicanism, Nueva York, Estados Unidos: Hill and Wang, 2002.

TAYlor, Charles, “Atomismo”. En su: La libertad de los modernos, Buenos Aires, Argentina: Amorrortu, 2005.

ZúÑIGA, Francisco, "Derecho de sufragio: la debatida cuestión de su obligatoriedad", en: Estudios Constitucionales, Año 7, N¹, 2009, pp.361-384. Talca, Chile: Centro de Estudios Constitucionales, Universidad de Talca. 